This is a self-archived version of an original article. This version may differ from the original in pagination and typographic details.

Author(s): Sharapan, Maria

Title: Tibetan Cultural Identity in Nepal : Change, Preservation, Prospects

Year: 2016

Version: Accepted version (Final draft)

Copyright: @ 2016 World Communication Association

Rights: In Copyright

Rights url: http://rightsstatements.org/page//nC/1.0/?language=en

Please cite the original version:

Sharapan, M. (2016). Tibetan Cultural Identity in Nepal : Change, Preservation, Prospects.

Journal of Intercultural Communication Research, 45(5), 374-390.

https://doi.org/10.1080/17475759.2016.1213180 
Tibetan Cultural Identity in Nepal: Change, Preservation, Prospects

\author{
Maria Sharapan, \\ Communication Department, University of Jyväskylä, Finland \\ masharap@s,student.jyu.fi
}




\section{Tibetan Cultural Identity in Nepal: Change, Preservation, Prospects}

In the difficult circumstances of institutional discrimination and political pressure, the Tibetan minority in Nepal negotiate their identity with utmost communicative resourcefulness, tying their values to universal ethics. They resort to their spiritual heritage in their daily intercultural encounters, seeing it mostly as an essential mindset. Developing intercultural personhood through universalization does not challenge identity salience, if one's culture is adhered to consciously. The respondents are optimistic about preserving their culture, provided the positive factors, such as community living and cultural education, persist. The obstacles are seen in materialistic influences, globalization and lack of interest among the young generation.

Keywords: Tibetans, Refugees, Cultural Identity, Identity Negotiation, Intercultural Personhood, Identity Preservation

\section{Introduction}

The preservation of the Tibetan cultural tradition is a truly important issue in terms of maintaining cultural diversity in the modern globalizing world. Particularly, the Tibetan culture enjoys massive popularity among non-Tibetans taking interest in the Buddhist spiritual tradition, as well as social, political and personal solutions based on ethical principles (Dorjee \& Giles, 2005; Erffa von, 1996; Frechette, 2002; Mountcastle, 1997). The ethical basis is grounded and reflected in this tradition, but surpasses its boundaries (Chukdong, 2006; Siderits, 1946; Tsering, 2006). The value which the global community can obtain from the Tibetan cultural tradition in the long run motivates to pose a question of how the tradition is being maintained by the culture- 
bearers. Considering external political circumstances (Sperling, 2004), as well as internal challenges of the cultural community and its members (Mountcastle, 1997), researching into the mechanisms of identity preservation or loss is essential to understanding the prospects of the culture in question.

This research is based on interviews with Tibetans in Kathmandu and Pokhara, Nepal, collected in the spring of 2013. This study looks into how the Tibetans negotiate their cultural identity in order to preserve it, what factors they see as beneficial and what challenges they may face. Maintaining one's culture in a host society presupposes balancing between the need to adapt, and the need to keep to one's roots (Dorjee, 2006; Kim, 2001). Some migrants may discover themselves oscillating between their traditional ways and values and the demands of the host culture, when those are in disagreement (Collie, Kindon, Liu, \& Podsiadlowski, 2010); others may face change in the next generation (Croucher, 2006). However, due to their philosophy and spiritual values, the Tibetans seem to be demonstrating a more elaborate approach to keeping this balance (Brox, 2010; Dorjee \&Giles, 2005). This article explores how TingToomey's $(1999,2005)$ dichotomy of identity consistency versus change manifests in the accounts of the Tibetan respondents. Ting-Toomey's (1993) idea of communicative resourcefulness, echoed in similar thoughts by Kim (2008) and Adler (1998), is meant to facilitate the adaptation process and transform it into an enriching experience. Tibetans are thought to devotedly follow the Buddha's Teaching (Dorjee \&Giles, 2005; Vahali, 2009), and these mental, attitudinal and behavioral stances may be adopted from the Mahayana Buddhist values and world outlook. Thus, this article also seeks to find out through interviews how and whether these values and ways influence their identity negotiation.

Tibetan cultural identity in Nepal is discussed further under six sections. Introduction 
includes a short historical background of the issue and a review of Tibetans' identity dynamics in exile studied by other authors. Theoretical background explains the notions of cultural identity, identity negotiation with an emphasis on stability vs. change dichotomy, and mindful intercultural communication in the context of this study. The choice of method, research participants, procedure, and data analysis is explained in the Method section. Further data presentation and analysis is provided in Results, Discussion and Conclusion sections.

\section{Historical Background}

Today Tibet is recognized as a part of the PRC (People's Republic of China) by the global community. Traditionally, Tibet consists of three provinces: Kham (Eastern Province), Amdo (North-Eastern Province), and U-Tsang (Central Tibet) (Dorjee, 2006). Today, Amdo and most of Kham provinces have been integrated into Chinese provinces; Tibet Autonomous Region (TAR) consists of U-Tsang and some parts of Kham. The current situation in Tibet arouses a lot of concern among human rights organizations, as well as ordinary Tibetans and their sympathizers, as Tibetan identity and civilization are under threat of extinction (Erffa von, 1996; Sperling, 2004; Tibet Center for Human Rights and Democracy [TCHRD], 2011). After Tibet lost its independence, the original cultural identity in Tibet was being deliberately eliminated during the Maoist Cultural Revolution, aiming to rid the society of the Four Olds: old customs, culture, habits, and ideas. For Tibet it implied elimination of religion, native language, traditions and dissent. After the death of Mao Zedong Tibetans gradually started to see some change: traditional clothes were allowed, the religious practice and worship ceased being a crime, the native language usage in public and education was resumed, and some of the destroyed six thousand monasteries began to be rebuilt by the consolidated efforts of the Tibetan people (Erffa von, 1996; Sperling, 2004; TCHRD, 2011). However, even now the political, economic and social 
situation in Tibet is far from a cultural renaissance. The forced inflow of Han Chinese has changed the ethnic landscape of the region, where native Tibetans are being marginalized. Mandarin has replaced the Tibetan language in education and employment. Religious institutions, teachers and monastics are subject to full state control and restrictions, forced to pledge allegiance to the Communist Party. Ordinary people are exposed to constant surveillance, and pro-government propaganda. Anything arousing the Party's displeasure, including keeping pictures of the Tibetan flag, the Dalai Lama, and other exiled leaders, exposes people to the risk of being arrested, imprisoned, tortured and killed (Human Rights Watch, 2015; TCHRD, 2014; Vahali, 2009). Considering the present circumstances in Tibet, maintaining the Tibetan cultural identity in exile appears to be crucial for the survival of the Tibetan culture in general.

\section{Identity Dynamics in Nepal}

Nepal, unlike China, has been tolerant or friendly to its traditional cultures, including the Buddhist ones, such as the Himalayan peoples (Singh, 2006). The Chinese occupation caused over a hundred thousand Tibetans to flee over the Himalayas to India and Nepal, where most of them settled and formed refugee communities. Nepal has been a transition point for most refugees, and is also kindred culturally (Bansh, 1992). The refugees established numerous Tibetan Buddhist monasteries and temples, which welcome not only ethnic Tibetans, but largely the indigenous Himalayan people, who share the same faith. The monasteries provide tremendous help in maintaining Tibetan identity and give religious education to monastics, regardless of ethnicity (Singh, 2006). Some of them, such as Kopan Monastery or Ka-Nying Shedrub Ling near Bouddhanath in Kathmandu, specialize in regular courses for Westerners coming from all over the world. This creates an impression of a lavish presence of Tibetans and Tibetan Buddhist culture in Nepal. However, the contemporary Tibetan community in the 
country is only about 15,000 people and is shrinking (Memorandum, 2011). The reason is deemed to be China's growing influence and restrictions on Tibetans living there resulting in discrimination and virtually impossible legal conditions for the Tibetan refugees. Nepal has been in political turmoil since the royal dynasty tragically stopped, and at the time of writing the biggest party is Maoist Communist. The formerly sympathetic and cooperative relations between the refugees and the local population have been undermined by political lobbying (Hatleback, 2010; Thapa \& Sharma, 2009). The refugee community receives a lot of foreign aid from NGOs and personal sponsors, and many Tibetans turn out to be successful entrepreneurs, which creates jealousy and distrust among the locals, who are not always aware of the real difficulties faced by the refugees and their families (Frechette, 2002; Prost, 2006). In Nepal they enjoy only restricted civil rights on the basis of an annually renewable refugee certificate (RC). The process of applying for and obtaining it takes considerable time and money, and only those who had arrived in Nepal before 1989 are entitled to one. Moreover, the RC restricts their rights to purchase property and grants only limited freedom of movement. Therefore, many Tibetans possess forged Nepali passports, creating serious risk when facing authorities (Tibet Justice Office, 2002; International Campaign for Tibet [ICT], 2011).

On the level of cultural identity the Tibetans in Nepal face a double challenge: on the one hand, they risk assimilation with the host culture, on the other hand, the moral and material aid from the west also brings moral and material temptations, as well as foreign values (Dorjee \& Giles 2005; Frechette, 2002; Hess, 2009; Mountcastle, 1997). The loss of native language command is a threat that Tibetans face in Nepal, even though they maintain close contacts with in-groups. Cross-marriages with relatively culturally kindred locals are another challenge for cultural preservation, especially for women, as this can be seen as an opportunity to obtain a 
Nepali citizenship. Receiving a lot of help and attention from Westerners, the Tibetans are exposed to standards of material comfort that do not accord with the reality of Nepal (Prost, 2006). The sponsors and NGOs, maintaining the community's economy, also bring in their values, such as liberalism, democracy, women empowerment, as well as undertake a responsibility of guiding the sponsored Tibetans in a way that best suits the sponsors' romanticized ideas of the Tibetan culture (Frechette, 2002; Mountcastle, 1997; Prost, 2006). These environmental, economic and psychological factors may cause assimilation, cultural rootlessness, attuning one's identity to foreign values, or, if faced mindfully, a constructive change, a balance between cultural rootedness and an open mind (Ting-Toomey, 1999). This research is based on 12 interviews with Tibetans residing in Nepal to discover how they maintain and negotiate their cultural identity. To approach and analyze their answers, theoretical and methodological perspectives are discussed below.

\section{Theoretical background}

\section{Cultural Identity}

The issue of cultural identity is a broad field, comprising various viewpoints and ideas, concerning what it is and how it can be defined. Cultural Identity Theory (Collier \& Thomas, 1988; Collier, 1998) revealed the issue from a phenomenological perspective, emphasizing the complex process of creating, negotiating and asserting cultural identity in communication with in-groups and out-groups. Collier's $(1988,1998)$ description was extended to include the importance of relational identity and facework (Cupach \& Imahori, 1993, 2005). A more detailed process of cultural identity negotiation was provided in the Identity Negotiation Theory (INT) 
(Ting-Toomey, 1999, 2005); particularly this research focuses on the dichotomy of identity consistency - change. In Ting-Toomey's (1999) definition cultural identity and ethnic identity represent two different categories, but from the INT perspective they do not form a contradiction. In this study the term 'Tibetan cultural identity' refers to both, the ethnicity and identification with the Tibetan culture. Ting-Toomey not only describes the dynamics of identity negotiation as such, but also looks into the processes, attitudes and skills, which form them. Due to their upbringing and spiritual values Tibetans may demonstrate these attitudes and skills naturally. Ting-Toomey (1999) asserts the ever-changing, circumstantial, and interactional nature of one's cultural belonging and self-conceiving, viewing identity "as reflective self-images, constructed, experienced, and communicated by the individuals within a culture and in a particular interaction situation" (Ting-Toomey, 2005, p. 217).

Interestingly, a similar seeing of identity or 'self' as devoid of rigid or inherent frames and characteristics is central to the Buddhist philosophy (Siderits, 2003/1947). The 'self' is not negated, but is seen as compound and dependent-arising (Giles, 1997). It is believed that if one overcomes the illusion of a solid independent 'self' and habituates oneself to this realization, it brings liberation from suffering. The absence of a solid, independent, unique self is proven by the compound nature of it, as Giles (1997) puts it:

According to Buddhist theory, what we call a person is really just an aggregation of the five skhandhas or elements. These are physical form, perceptions, feelings, motives, and consciousness. But none of these elements, whether considered separately or in combination, can rightly be identified with the self, for they lack the various qualities we attribute to the self [meaning permanence and independence]. (p. 142) 
Instead, 'self' is seen as ever-changing and arising dependently according to karma, cause and effect. The Buddhist concept of 'selflessness' can hardly be presented in a nutshell without causing confusion and misunderstanding, and usually requires rigorous study and practice to conceive. However, the general idea of 'self' or identity as being dependent-arising (rather than independent), compound (rather than solid), and ever-changing (rather than permanent), is likely to have an impact on the values and upbringing of Tibetans, who are naturally exposed to the Buddhist tradition.

\section{Identity Stability versus Change}

The vibrant and ever-changing nature of cultural identity is reflected particularly in identity negotiation. In her IN theoretical assumptions Ting-Toomey $(1999,2005)$ provided a number of dichotomies, illustrating the IN processes. The change, preservation and prospects of the Tibetan cultural identity can be analysed through the dichotomy of identity stability versus change. According to IN, a healthy balance presupposes oscillation within a tolerable range of consistency (rootedness) and change (rootlessness). Feelings of separation and hostility with the host environment may strengthen clinging to one's identity, fortifying identity consistency. Oscillating too much towards identity change, on the other hand, is said to cause rootlessness and deprive an individual of the 'moral center' (Ting-Toomey, 1999, p. 144), as well as undermine relations with in-groups. However, with a certain amount of mindful attitude, emotional intelligence and behavioral skills, Ting-Toomey $(1993,1999)$ argues, one can achieve balance to connect the edges and stimulate personal growth, bringing about a positive change. The first question posed here inquires how the oscillation happens, and what kind of change the Tibetans observe in their cultural identity as a result. RQ1: What change do Tibetans in Nepal report to observe in their cultural identity in intercultural encounters? 


\section{Mindful Intercultural Communication}

The key to successful identity negotiation lies in communicative resourcefulness, which consists of three components: knowledge, motivation and skills (Ting-Toomey, 1993; 1999). The first component refers to attitudinal factors, including mindfulness, balanced categorization without stereotyping, and enriching intercultural experience (Ting-Toomey, 1993). The motivation component includes affective factors, such as empathy, attuning to cultural environment, and balancing self- and other-focused emotions (Ting-Toomey, 1993). The third component presupposed finding appropriate behavioral patterns to match the first two. Ting-Toomey (1993) claims all the three components are rooted in the ethical resourcefulness, i.e. an ability to discover and emphasize common and universal ethical values (Ting-Toomey, 1993).

This paradigm is parallel to concepts introduced by other authors. Dai (2009) links TingToomey’s (1993) concept to Kim's (1998) Intercultural Personhood (IP), which is seen as 'not defined rigidly by any single culture', 'open to further transformation' and 'representing a high degree of psychic evolution' (Dai, 2009, p.2). IP has three stages: unconscious, conscious and creative. Dai (2009) critically points out that the process of individuation and universalization required to achieve this intercultural identity is likely to lead to acculturation and deculturation. According Ting-Toomey $(1999$, p. 44) too much identity change may lead to rootlessness, loss of cultural values, and even marginalization. However, both Kim (1998) and Adler (1998) introduce their similar concepts with the opposite claim: at the highest stage such personhood presupposes a strong commitment to their own cultural uniqueness. Adler's (1998) concept of Multicultural Man received even more criticism in Dai's (2009) analysis, being accused of 'cosmopolitanism' and ignoring historical and cultural differences. Adler (1998) introduces his concept on the example of real cultural and historical personalities, who were able to overcome cultural 
boundaries, however, the implications for cultural identity stability may in fact be negative, as Dai (2009) pointed out. The example of how and whether these parallel paradigms manifest on the self-reported intercultural experience of Tibetans may provide a good insight into these theoretical concepts and their mechanisms.

In light of the above theoretical discussion of communication resourcefulness, its potential rootedness in spiritual values, importance of religion to Tibetans, and challenges they face in diaspora to preserve their culture and identity, three interrelated research questions are asked: RQ2: How much communicative resourcefulness can be traced in how Tibetans describe their identity negotiation? RQ3: What is the role of their spiritual view in forming their communicative resourcefulness? RQ4: How do Tibetans describe the role, means and prospects of preserving their cultural heritage?

\section{Method}

This study is based on a master's research conducted in Kathmandu and Pokhara, Nepal in 2013. The two cities are the largest in Nepal and the only ones accommodating a substantial Tibetan community. The fieldwork and research procedures received an appropriate ethical approval before the data was collected. To answer the research questions, 12 structured interviews (30-60 minutes long) with men and women from both cities were conducted. The structured interviews outlined the answers in a stricter fashion, which would better respond to the research questions. The interview guide is attached. The qualitative approach allowed the study to obtain an in-depth view into the Tibetans' identity negotiation in its complexity (Barbour, 2013; Treadwell, 2014). Quantitative studies previously done on Tibetan exiles (Evans et. al, 2007; Sachs, Rosenfeld, Lhewam Rasmussen, \& Keller, 2008; Yankey \& Biswas, 2012) do not provide deep understanding of how Tibetans think and feel about their identity and identity negotiation in 
diaspora. Besides, all of the mentioned studies were conducted in India, where the environment is supportive of the refugees. Collecting large data in Nepal was nearly impossible due to the circumstances described in previous sections. This can potentially form a limitation for this study, as well as further studies focused on Tibetan minority in Nepal.

\section{Respondents}

The respondents included four activists, two heads of settlements (Jampa, Tsering), two monastics, an NGO director (Dechen), a meditation center administrator, a language teacher and a school headmistress. Table 1 below includes more demographic information (coded name, gender, approximate age, residence status, occupation) for respondents from both cities.

\begin{tabular}{l|l|l|l|l|l|l|l|l|l}
\multicolumn{1}{l}{ Kathmandu } & \multicolumn{1}{l}{ Pokhara } \\
\hline Karma & $\mathrm{m}$ & 37 & refugee & activist & Dechen & $\mathrm{f}$ & 46 & refugee & director \\
\hline Dawa & $\mathrm{m}$ & 35 & refugee & activist & Sonam & $\mathrm{m}$ & 22 & born in Nepal & student \\
\hline Tenzin & $\mathrm{m}$ & 45 & born in Nepal & monastic & Dorje & $\mathrm{m}$ & 66 & refugee & activist \\
\hline Ani la & $\mathrm{f}$ & 33 & refugee & monastic & Jampa & $\mathrm{f}$ & 34 & refugee & director \\
\hline Tinley & $\mathrm{m}$ & 32 & refugee & teacher & Tsering & $\mathrm{m}$ & 45 & refugee & director \\
\hline Pema & $\mathrm{f}$ & 52 & refugee & headmistress & Norbu & $\mathrm{m}$ & 30 & born in Nepal & administrator
\end{tabular}

Table 1 Research participants (coded names)

\section{Procedures}

Reaching the informants was more difficult than expected, because my fieldwork followed a selfimmolation ${ }^{1}$ by a Tibetan monk in Kathmandu. Due to ongoing police checks Tibetans were quite distrustful of strangers, so obtaining the data required ice-breaking and rapport-building

1 An act of setting oneself on fire in order to express protest, practiced in some Buddhist cultures, particularly by modern Tibetans, both in the PRC and in exile. As of December 2015, 143 Tibetans have committed selfimmolations. 
procedures: acceptance by settlement authorities, references, talking before the interviews, respondent's choosing place and time for the interview. I contacted Tibetan schools and settlement offices by email, phone, and visited them personally in order to find respondents. Lindlof and Taylor (2002) recommend using snow-ball sampling in case of elusive population, but very often the interviewees refused to involve their contacts for safety reasons. Besides, purposeful sampling was preferable in order to obtain broader information (Lindlof \& Taylor, 2002), as the chosen respondents had some experience of cooperating with locals and Westerners, and, therefore, they could contribute significantly more to the study.

\section{Data Analysis}

The interviews were recorded, transcribed and analyzed using thematic analysis and fixed coding, i.e. the categories were created on the basis of the theory and context. The interview answers were analyzed to illustrate or challenge the theoretical assumptions (Braun \& Clarke, 2006; Treadwell, 2014). The points underlying the categories were: dichotomy of identity stability versus change, Ting-Toomey's (1993) communicative resourcefulness and Dai's (2009) critical analysis of Kim's (1998) intercultural personhood and Adler's (1998) multicultural man, manifestations of ethical resourcefulness, which was supposed to underlie communicative resourcefulness (Ting-Toomey, 1999), the role of spirituality, and, finally, the respondents' own ideas about preservation of their cultural identity in exile.

\section{Results}

RQ1: What change do Tibetans in Nepal report to observe in their cultural identity in intercultural encounters? Two themes that emerged in response to RQ1 were identity 
consistency and identity change. About a half of the respondents said with different levels of certainty that their cultural identity remains consistent: 'Nothing has been changed, we're all the same'; 'In fact, I feel like we are becoming stronger here'. The monastics said they did not see any major identity change or transformation as their lifestyle was very traditional. Activists Karma and Dawa pointed out that there was outer change due to the restrictions to gather, but internally Tibetans did not become or feel less Tibetan. In fact, the restrictions made the essence of being Tibetan stronger: 'I feel like there's more culture within us, like there is a suffering inside, that we should keep the culture, religion all these things'. Cultural salience and identity stability are also fortified by external avowal that they eagerly confirm: 'we are the key moral people in Nepal'; 'many people respect'; 'we are doing very well because of hard work and honesty'. Some mention education to be the first point of transformation for Tibetans in exile, and also cultural exchange, political and social changes as a result of encountering other cultures. Sonam is definitely positive about his 'internal transformation', praising the introduction of a democratic system, and suggesting in an independent Tibet he would not 'be working with a laptop', but 'would be a cowboy'.

In terms of identity stability Nepal appears to be a more beneficial place, than the West. The relations between the local population and Tibetans are described as 'cooperative', 'very emotionally comfortable' and 'friendly', regardless of possible differences. The size of the Tibetan community, the settlement structure, the vicinity of cultural and religious objects and the interest of foreigners, on the other hand, serve as positive factors. In contrast, as Norbu and Dechen mention, living in the West demands struggling for higher living standards and does not leave 'much opportunity to gain Tibetan culture from the parents, and the parents used to be busy'. Norbu is happy he 'hadn't got tricked', recalling the experiences of his peers who 
emigrated to the West. In the highly competitive environment, isolated from their community, Tibetans may face the option of assimilation instead of mutual valuation.

RQ2: How much communicative resourcefulness can be traced in how Tibetans describe their identity negotiation? The three themes which can be identified in the answers coincide with the three levels of Ting-Toomey's (1993) communicative resourcefulness: attitude, emotions and behavior. Dawa explains the historical uniqueness of every culture, due to differences in upbringing and circumstances, concluding 'we have to adapt', illustrating the mental level. Other respondents also pointed out mutual respect, learning and cultural exchange, importance of global responsibility over cultural background, and seeing culture as a 'man-made' thing. A settlement director Jampa, a woman in her thirties, says: "The word human doesn't mean that you are American, or Japanese. You are human, I am human. I am respecting your value, you are respecting my value, there's no contradiction, there's always harmony there." Her vision exemplifies emotional level. It is reiterated by many other respondents, who mention that people deserve respect and cherishing regardless of their culture. They claim every culture is 'beautiful' and suitable to its representatives. Lastly, it manifests on behavioral level, which means creative use of suitable behavioral patterns for protecting personal and group face and achieving intercultural goals. The actions mentioned by the respondents include talking sensibly to the police and locals, helping the community, keeping strict discipline in the settlements, attending local festivals. Dawa says:

My own individual approach is working. I don't know others, but this is dependent on how you just compliment and express, how you just make them that is right. (...) The police and people who beat me, I success to this. If your attitude is positive, and you're going to solve the problem, most of time you will do it. 
Other activists and NGO director Dechen confirm his experience. This way, all the three levels appear to be well-mastered.

However, communicative resourcefulness correlated with Kim's (2008) and Adler's (1998) concepts with a slight variety. Bringing up Adler's (1998) concept, discussed in the theory review, Sonam exemplifies a multicultural man. He was born in Nepal, studied social sciences at a Nepali university, married a Nepali, spoke Nepali better than Tibetan and had a lot of Nepali friends. He considered himself Buddhist, but said he respected all traditions, would go to Hindu temples to pray, and used theistic terms, foreign to Buddhism, to explain his belief. At the time of the interview, Sonam was leaving to study abroad, spoke excellent English, and was known in the settlement as an ardent fighter for the Tibet cause. The multicultural thinking behind Sonam's lifestyle and actions is reflected in his own words: "If we are shouting that my culture is great, your culture is not, my religion is great, your religion is not. That is outfashioned, outdated, expired ideas". Sonam also mentions that cultural differences can be 'misutilized' politically and claims 'debate in the name of culture' to be a 'sign of foolishness'. For Sonam being open to different cultures means 'feeling and sharing the culture of different people' and practical learning, and the same concerns religion as well. According to Sonam, this broad attitude does not change his 'Tibetan heart', but he wants to learn 'things about others'. Sonam agrees with most respondents, saying that the main thing to be preserved about the Tibetan culture is religion, which he defines as 'the constitution of your heart'. However, he himself admits being very assimilated by the host culture in terms of language and customs.

Two activists, Dawa and Karma demonstrate a high degree of universal outlook, panhuman values, and global responsibility. They say: "Generally we are all the same, just we both need love and don't want to be in suffering", so our common responsibility is "to save this 
planet, preserve this humanity, preserving truth". Their answers show that 'same' means not uniform, but equal. Therefore, the universalism they are speaking about does not eliminate cultural differences, but rather it celebrates the cultural variety, exchange, and learning, creating space for different cultures to co-exist as different in form and essence, but equal in rights and importance. A step towards universalization does not seem to affect Karma's identity stability. Another activist, Dorje from Pokhara, expresses a similar global attitude, keeping loyal to his own culture. He expresses a wish for a 'one world', where 'we have the truth and everybody speaks peace'. Speaking of cultural exchange, he recalls his experience of a yoga retreat at a Hindu Sri Sri Ravishankar centre, where '1600 people' from different cultures gathered to do yoga, without any 'complaints', with no shopkeeper to watch people pay for goods, and calls it a 'heavenly, peaceful world'. Although it was a different culture for him, he said: "That gave me such platform to my Buddhist belief".

Three other respondents: an NGO director, a settlement director and a teacher, also demonstrate a similar stance, putting common human core over cultural differences, however without stressing cultural universalism. A language teacher Tinley admits seeing cultures as 'different', but thinks they should not compete in importance, but learn from each other. The importance of cultural exchange and education is also mentioned by monastic interviewees, who stressed the value of travelling and seeing the 'specialty' in a foreign culture.

Three interviewees, however, did not show the same openness. Norbu, a meditation center administrator, said he was not motivated to engage in cultural exchange with locals or Westerners, saying: "I'm very much satisfied with what I have, and it helps me a lot with myself". However, he suggested he can 'open to it', if he is interested. Pema, a school headmistress, implicitly shows a similar view. She talks very highly about Tibetan culture, and 
admits Tibetans to be the only people she could trust ahead of knowing them well, and when asked about attitude to other cultures, she reiterates her motto: "Live and let others also live".

The third example was a settlement director, Tsering. Tsering speaks a lot about intercultural harmony, respect for human essence, but when talking about relations with the locals and with Westerners, he does not seem to demonstrate the first, mental level of Ting-Toomey's (1993) communicative resourcefulness, i.e. ability to categorize without stereotyping. He was exalting Tibetans, Tibetan culture, their peace and harmony, and their ardent, but wise struggle against the blatant injustice of the situation in Tibet and in Nepal by means of the Middle-Way Approach. However, speaking about Westerners, Tsering was not so generous and open-minded: "They have so many dollars in a bank, so many properties, so many cars, in reality, innermost they always treat angry, because they can't produce inner love, they don't feel compassion, they never respect for others". He claimed Tibetans 'are far more higher developed (...) as far as thinking power is concerned'; and talking about locals he said Tibetans have ' $100 \%$ cultural difficulties' because of ethnic and traditional differences. He tried to illustrate his example of 'when in Rome do as Romans do' by saying I should not take my fur hat and husky dog when going from Russia to Finland, because 'this is Finland, there is no snow'. This way, in Tsering's case, ethnocentrism, lack of tolerance to other cultures and rash judgements sound contradictory to his philosophy, which may mean that these values are not fully internalized.

\section{RQ3: What is the role of their spiritual view in forming their communicative}

resourcefulness? The paradigm of communicative resourcefulness, according to Ting-Toomey $(1993,1999)$, was to a large extent rooted in the understanding of the universal moral values. The results demonstrate very clearly that referring to human ethics could be often used as a strategic tool of one's identity negotiation. The following themes emerged in response to RQ3: 
Buddhist values (belief in the law of karma, impermanence, non-violence) and practical belief. Karma mentioned Tibetans are seen as 'the key moral people in Nepal'. He said, when they are arrested during a demonstration they try to apply gentle moral pressure on the police. Facing violence, they appeal to common sense and human nature of the police, who beat and arrest them. Dawa brought an example of how he was telling a policeman about his responsibility and constructive work for Nepal, because he had the same 'worries' for it, as he lived in this place. They also face a vital necessity to maintain this image by avoiding common and criminal clashes of any kind: it is done not only on the personal level, but also on the level of regulations and restrictions in the settlements.

The assumption that the ethical resourcefulness, demonstrated by the Tibetans, may be rooted in their spiritual values seems to be confirmed by the responses. When asked about how their religious belief helps them in controversial situations with non-Tibetans, most respondents said that it helped greatly in their life in general, not only in some particular situations. The first thing that most people mention is patience, i.e. ability to handle negative emotions and tolerate difficult conditions. The majority of respondents mention the belief in the law of karma as the factor that gives them this power, thinking 'maybe we did something bad in the past, so we have to bear it because of ourselves'.

Other factors that help them deal with difficult situations are thinking about Buddhist 'meditation on emptiness' and concept of impermanence, 'sometimes come and sometimes go'. Thinking of interdependence also makes them do their best for others, as Dechen says:

We say we will struggle for our freedom, but in a positive way. Nonviolence way. So we create positive karma, so we can have, at least in our future life, positive result, not only 
future, even in this life. We are enjoying positive results, because many people respect.

This belief makes them feel peaceful in the difficult circumstances they are caught in. Although they 'have no more freedom and so much pressure', they say 'some Tibetans are even happier than the local people', 'because of the spiritual'.

Most Tibetan respondents stress that their belief is not based merely on faith, but has to be 'practical'. The conviction in the power of the human mind, interconnection and good qualities win over traditional religious premonitions: "If there's reason and logic in religion, I believe"; "I believe in religion, but I never want to believe a religion in orthodoxical way"; "We are not so supersensitive, we are not so dogmatic, you know, orthodox. We are not so... conservative".

RQ4: How do Tibetans describe the role, means and prospects of preserving their cultural heritage? The Tibetans were asked about the most important aspects to preserve in their culture, how it is and can be preserved, challenges and ways. The elicited themes were religion, language, and desire to return to Tibet (aspects to preserve), globalization and assimilation (challenges), and cultural indoctrination (suggested means).

The aspect that is mentioned by all Tibetans is the religion, 'because the religion is like heart and brain in a human body'. However, almost all respondents see the religion first of all as an attitude, and a value system, not as a formal tradition. They say 'our religion' is the Dalai Lama's advice 'do not harm'. Pema was the only respondent to mention the ritualistic part of the practice: "They go to the monasteries, and they respect statues of gods and goddesses. Even in our school we have our daily prayers in the morning, before we eat, we offer to gods or goddesses". Another important aspect to preserve is the Tibetan language, both colloquial and classic. They believe by preserving the religion they will preserve the language as well, and by 
preserving the 'language script' they can preserve other 'culture parts'. The third aspect of Tibetan culture to be preserved, according to the Tibetans, is the desire to return back to Tibet. Respondents express the need to maintain connection with their homeland, 'suffering' to return back, and a hope to resume their culture there: 'We have to reach there, and then we can preserve our culture slowly'.

The factors that create challenges to preserving the culture are seen in the increasing outer materialistic influences, not as much from the host society as from the Western, global culture. Sonam explains it by the general trend of globalization: 'Gradually in course of time, not only of Tibetan culture, even Muslim, Arabic culture will be mixed in one culture: Western culture'.

Norbu sees that the Tibetan culture is more complicated, compared to popular values:

(...) the younger generation needs something more simple they are able to understand and put into practice. At least some faith may come out. So because of lack of this, some kids tend to go to this materialist. Because it's easier to go that way, body comfort, body pleasure, who doesn't want? Everybody wants!

He also mentions another reason why both language and religion are endangered: young people do not understand the Tibetan language, in which the teachings are given. He said that he understands Buddhist teaching in English much better than in his native Tibetan, because 'all the teachings are done in text language'. Sonam acknowledges, saying 'I cannot speak Tibetan well', because he grew up in Nepali society. On the personal level two respondents also mentioned marriages with non-Tibetans as a threat to preserving one's culture, as Dechen says: "Obstacle is, if one goes out of Tibetan community and gets married with the other culture's people, like Nepali or Westerner. Then I think, he or she might change or lose his identity". The positive 
factors are keeping community, sharing cultural values in the family, educating the younger generation, 'if the Tibetan culture is taught by Tibetan teachers ... from primary school level up to college level'.

Interestingly, although in an off-record conversation, my first respondent Pema apprehended Tibetan culture to 'be diluted', for the record all the respondents expressed a generally positive feeling about the preservation of their culture.

\section{Discussion}

The first focus of the study was the nature of identity change Tibetans observe in Nepal. The interview answers demonstrate that in the difficult circumstances of exile and discrimination Tibetans may feel stronger identity salience, swaying to the side of identity consistency. However, the respondents tended to keep their minds open to new cultural ways, and to take advantage of international contacts and modern education, which creates a constructive change on personal and social levels. Apart from this positive drive, which sways them to the edge of identity change, there is also the challenge of materialism and globalization. These findings illustrate Ting-Toomey's (2005) assumption that a mindful and healthy identity negotiation is marked by balancing between identity consistency / rootedness and identity change / rootlessness, avoiding the edges, allowing for constructive change without sacrificing one's culture.

The second question inquired into how communicative resourcefulness manifests in the respondents' answers. The results demonstrate that all the three levels of communicative resourcefulness (Ting-Toomey, 1993) are employed in their intercultural encounters. In congruence with Ting-Toomey's (1999) emphasis on ethical resourcefulness, appealing to universal human 
values and global responsibility was broadly used by the Tibetans as an asset, as they maintain their good record and employ group face keeping.

Some answers also illustrate the ideas of multicultural man (Adler, 1998) and intercultural personhood (Kim, 2008). These two concepts are very closely related, but as Dai (2009) points out, the first one may practically prove to challenge a person's own cultural belonging, and make them rootless. One of the respondents, Sonam is a good example of Adler's (1998) multicultural man. While his own example may be in accord with Adler's (1998) ideal, most probably, if every Tibetan treated their culture with the same openness, it would be a big challenge to preserve it. A few more respondents seemed to be making a step from individuation to universalization in their reasoning, which resonated with the idea of Kim's (2008) intercultural personhood. Although Dai (2009) suggested that similarly to Adler's (1998) multicultural man, intercultural personhood may also lead to rootlessness, or at least a decrease in cultural salience, the answers sounded clearly disproving of this statement. This results imply that conscious adherence to one's own cultural values may not be an obstacle to developing intercultural personhood, as long as one's own cultural values are seen as being accordant with universal human values and worth adhering to.

The third focus was the significance, nature and role of the Tibetans' spiritual view and practice. The spiritual element in their life was seen as important by all respondents. Apart from providing a robust ethical beacon, it brings patience and tolerance by understanding the cause-effect relations and impermanence; it gives meaning to their life and their activity through understanding that they are creating causes for good results in the future for themselves and other people; it highlights the connection and co-dependence of all human beings, increasing empathy and benevolence to others. The interviewees felt that patience and tolerance allowed them to balance self-focused and other-focused emotions. The interdependent nature of 'self' was not men- 
tioned by the respondents, but many spoke about panhuman values and common human core, which is more important than the labels of culture, language, religion and gender. This way the open-minded non-dogmatic religious attitude can be seen as increasing empathy, reflexivity, mindfulness, and patience, thus forming the so-called ethical resourcefulness (Ting-Toomey, 1999), which helps the Tibetans in their intercultural encounters.

Finally, the last question concerned the role, means, challenges and prospects of preserving the Tibetan cultural heritage in Nepal. The Tibetans emphasize the global importance of preserving their cultural heritage, as well as national. According to the respondents, the three most important aspects to be preserved are religion, language, and the desire to return to Tibet. Religion means primarily to philosophy and values, while rituals and dogmas are seen as secondary. The importance of language is especially seen in preserving their religious tradition. Finally, the longing for Tibet is seen as allegiance to their roots, to their history and origins. Materialism, Western influence, globalization, language assimilation, and marriages with out-groups are mentioned as hindrances. The positive factors are settlement living, promoting traditional values and customs at home and at school, studying the language and Buddhism. Creating families within the community may be another efficient contribution to the preservation of their culture, as compared to out-group marriages.

Although the general feeling coming out of the interviews is positive, it is important to realize the impact of various factors on the preservation of the Tibetan culture. By obstructing the integration for Tibetan refugees in the host society the Nepali government creates segregation, which is not solely negative. The Tibetans have to constantly renegotiate their identity, reiterate their importance for Nepali society and the global community, not only verbally but also by actions. The unfair civil position has an upside of preventing Tibetans from dissolving into the multi-ethnic melting pot of Nepal. They do not face many challenges of cultural or religious dif- 
ferentiation, which makes it possible for them to make use of the cultural and religious similarity to negotiate their rights.

\section{Limitations of Research}

Despite the significance of the conclusions for future research in the area, there are several limitations to this study. First of all, the study is not devoid of common limitations of a qualitative research, such as sampling and generalizability (Treadwell, 2014). The accessible respondents mostly belonged to Tibetan elites, whose situation and way of thinking can differ from that of the more common population. The choice of respondents may not be very representative of the community, but two upsides were English language proficiency and the knowledge of the situation. Second, there results may have some response bias. The stories, impressions and ideas told by the refugees acquire layers of interpretations (Eastmond, 2007), and apart from that some interviewees could be keen to create a desirable impression of Tibetan culture. Nevertheless, the study reveals common trends, which may be of significant help to and a good basis for further research, which can be conducted with the Tibetan minority population in Nepal, using broader sampling and native language.

\section{Conclusion}

As the study has shown, the Tibetan refugees in Nepal are able to maintain their cultural identity, mindfully balancing identity rootedness with constructive change (Ting-Toomey, 1999). The main transformation is seen in access to education and enriching intercultural experience, however, a few also mentioned the influence of material values. Confirming Ting-Toomey's (1999, 2005) suggestion that mindful identity negotiation depends on communicative resourcefulness, based in ethical resourcefulness, the Tibetans demonstrated all the three levels: mental, emotional 
and behavioral (Ting-Toomey, 1993), and respect for universal human values. Making the step from individuation to universalization (Kim, 2008) is common for many respondents, but intercultural personhood does not usually endanger their feeling of cultural belonging, if native culture is deliberately valued and adhered to. The aspects of their culture worth preserving are named to be: religious values, language, and the allegiance to Tibet. The factors, enhancing the preservation of the Tibetan culture are thought to be community and settlement living, education, in-group marriages, and staying in bigger refugee communities. All the respondents were optimistic about their cultural longevity.

This study suggests some directions for future research. First, the generalizability of these research findings to Tibetan diasporas in Nepal and India can be further checked. Second, the significance, the nature of religious belief and practice among Tibetan diasporas, as well as its role in preserving cultural heritage can pose interesting questions for further research. Last but not least, studies need to be done on the influence of assimilative factors, such as host culture language use.

\section{Acknowledgements}

The author would like to thank the Tibetan activists and settlement leaders for their trust and cooperation, as well as Dr. Tenzin Dorjee, University of California, for his helpful comments and suggestions. 


\section{References:}

Adler, P. S. (1998). Beyond cultural identity: Reflections on cultural and multicultural man. In Gary R. Weaver (Ed.) Culture, communication and conflict: Readings in intercultural relations. Needham Heights, MA: Ginn.

Bansh, J. H. (1992). Tibetans in Nepal. South Asia Books.

Barbour, R. (2008). Introducing qualitative research: A student's guide to the craft of doing qualitative research, Sage Publications UK.

Braun, V., \& Clarke, V. (2006). Using thematic analysis in psychology. Qualitative Research in Psychology, 3, 77-101. Retrieved from: http://eprints.uwe.ac.uk/11735/2/thematic analysis_revised

Brox, T. (2010). Changing the Tibetan way? Contesting secularisms in the Tibetan diaspora. In Saadet Arslan \& Peter Schwieger (eds.): Tibetan studies. An anthology. Halle: IITBS, (pp. 117-42).

Chukdong, K. (2008). A Human family: a modern Tibetan Buddhist perspective. Author House.

Collie, P., Kindon S., Liu, J., Podsiadlowski, A. (2010). Mindful identity negotiations: The acculturation of young Assyrian women in New Zealand. International Journal of Intercultural Relations, 34, 208-220.

Collier, M. J. (1998). Researching cultural identity. In D. V. Tanno \& A. Gonzalez (Eds.), Communication and identity across cultures, (pp. 122-147). Thousand Oaks, CA: Sage.

Collier, M. J., \& Thomas, M. (1988). Cultural identity: An interpretive perspective. In Y. Y. Kim \& W. B. Gudykunst ( Eds.), Theories in intercultural communication, 94-120. Newbury Park, CA: Sage. 
Croucher, S. M. (2006). The impact of external pressures on an ethnic community: The case of Montréal's Quartier Chinois and Muslim-French immigrants. Journal of Intercultural Communication Research, 35, 3, 235-252.

Cupach, W. R., \& Imahori, T. T. (1993). Identity management theory: Communication competence in intercultural episodes and relationships. In R. L. Wiseman \& J. Koester (Eds.) Intercultural communication competence, (pp. 112-131). Newbury Park, CA: Sage.

Cupach, W. R., \& lmahori, T. T. (2005). Identity management theory: Facework in intercultural relationships. In Gugykunst W. B., Theorizing about intercultural communication, (pp. 195-210). Sage Publications.

Dai, X. D. (2009). Intercultural Personhood and Identity Negotiation, China Media Research, $5-2$.

Dorjee, T. (2006). Transmitting cultural identity from generation to generation in Tibetan diaspora. In W. Leeds-Hurwitz (Ed.) From generation to generation: Maintaining cultural identity, (pp. 227-253). Hampton Press.

Dorjee, T., \& Giles, H. (2005). Cultural identity in Tibetan diaspora. Journal of Multilingual and Multicultural Development, 26, 138-157.

Eastmond, M. (2007). Stories as lived experience: narratives in forced migration research. Journal of Refugee Studies, 20, 2.

Erffa von, W. (1996). Uncompromising Tibet: Culture, religion, politics, Paljor Publications.

Evans, D., Buxton, D. C., Borisov, A., Manatunga, A.K., Ngodup, D., Raison, C. L. (2008). Shattered Shangri-la: differences in depressive and anxiety symptoms in students born in Tibet compared to Tibetan students born in exile. Social Psychiatry and Psychiatric Epidemiology, 43, 429-436. 
Frechette, A. (2002). Tibetans in Nepal: the dynamics of international assistance within a community in exile, Berghahn Books.

Hatlebakk, M. (2010). Maoist Control and Level of Civil Conflict in Nepal. South Asia Economic Journal, 11, 1, 99-110.

Hess, J. M. (2009). Immigrant ambassadors: Citizenship and belonging in the Tibetan diaspora, Library of Congress.

Human Rights Watch. (2015). World report. Retrieved from https://www.hrw.org/worldreport/2015/country-chapters/china?page $=1$

ICT, International Campaigh for Tibet. (2011). Dangerous Crossing, Conditions impacting the flight of Tibetan refugees. Retrieved from: http://www.savetibet.org/dangerous-crossing2011-update/

Kim, Y. Y. (2008). Intercultural personhood: Globalization and a way of being. International Journal of Intercultural Relations, 32, 359-368.

Lindlof, T. R., Taylor, B. C. (2002). Qualitative communication research methods. 2nd ed. Sage. Library of Congress.

Memorandum of Tibetan refugee welfare office. (2011). Lazimpat, Kathmandu Mountcastle, A. (1997). Tibetans in Exile: the construction of global identities, UMI dissertation services, New Brunswick, New Jersey.

Prost, A. (2006). The problem with 'rich refugees' sponsorship, capital, and the informal economy of Tibetan refugees. Modern Asian Studies, 40, 233 - 253.

Sachs, E., Rosenfeld, B., Lhewa, D., Rasmussen, A., Keller, A. (2008). Entering exile: Trauma, mental health, and coping among Tibetan refugees arriving in Dharamsala, India. Journal of Traumatic Stress, 21-2, 199-208.

Siderits, M. (2003/1946). Personal Identity and Buddhist Philosophy, US Library of Congress. 
Singh, H. L. (2006). Brief Encyclopedia of Buddhism in Nepal, Ratna Pustak Bhandar.

Sperling, E. (2004). The Tibet-China conflict history and polemics. Policy Studies 7. East-

West Centre, Washington.

Thapa, G. B., Sharma, J. (2009). From insurgency to democracy: The challenges of peace and democracy-building, International Political Science Review, 30, 205-219.

Tibetan Centre for Human Rights and Democracy. (2011). Imposing modernity with Chinese characteristics: the fate of Tibetan civilization. TCHRD.

Tibetan Centre for Human Rights and Democracy. (2014). Annual Report 2013. Retrieved from: http://www.scribd.com/doc/200837998/2013-Annual-Report-Human-Rights-Situation-inTibet\#

Tibet Justice Office. (2002). Tibet's stateless nationals: Tibetan refugees in Nepal. Retrieved from: http://www.tibetjustice.org/reports/nepal.pdf

Ting-Toomey, S. (1993). Communicative resourcefulness: An identity negotiation perspective. In R. L. Wiseman \& J. Koester (Eds.). Intercultural communication competence. (pp. $72-$ 111). Newbury park, CA: Sage.

Ting-Toomey, S. (1999). Communicating across cultures, Library of Congress Cataloging-in Publication Data.

Ting-Toomey, S. (2005). Identity negotiation theory: crossing cultural boundaries. In W. B. Gudykunst (Ed.) Theorizing about intercultural communication, Thousand Oaks, CA Sage.

Treadwell, D. (2014). Introducing communication research: paths of inquiry. 2nd ed. Sage. Library of Congress.

Tsering, T. G. (2006). Buddhist Phychology, Library of Congress Cataloguing. Vahali, H. O. (2009). Lives in exile: exploring the inner world of Tibetan refugees, Routledge 
India and UK.

Yankey, T., Biswas, U. N. (2012). Life skills training as an effective intervention strategy to reduce stress among Tibetan refugee adolescents. Journal of Refugee Studies. 25, 4, 514 536. 


\section{Appendix A}

Interview questions:

1. What does it mean to be Tibetan for you?

2. How, do you think, you are perceived by local Nepali people? $+/-$ ?

3. How are you seen by Westerners? Is it close to reality?

4. Do you feel any cultural difference with non-Tibetan people in Nepal? What? Examples?

5. How close do you see local people compared to other Tibetans? And Westerners?

6. How emotionally comfortable do you feel with local people compared to other Tibetans? And with Westerners?

7. How much trust do you feel to the local people compared to other Tibetans? And with Westerners?

8. Do you have / have you had any close friendship or even love relationships with nonTibetan people? If yes, how do you feel compared to those with other Tibetans? If no, do you think it could be possible? Why?

9. Can you remember any controversial situations with local people or with Westerners? For example, when you felt it hard to be Tibetan? How did you behave and feel? What, do you think, were the reasons for misunderstanding?

10. What is your attitude towards culturally different people in general?

11. Do your religious beliefs and/or spiritual practice help you in controversial situations? How?

12. What, do you think, is the right way to treat culturally different people? Does it work in real life? 
13. What transformation do you see in yourself and other Tibetan people, when you live in Nepal?

14. Do you feel that you are becoming more open-minded to other cultures? If yes, does it challenge or strengthen your cultural uniqueness?

15. Do you feel like you and other Tibetan people you know here are becoming "less Tibetan" or the opposite?

16. What aspects of your culture do you think are the most important to preserve in yourself and in your (future) children?

17. What do you think are the prospects for the Tibetan culture? Do you feel that people can preserve it in the future? How? What could help? What can be the challenges/obstacles? 